\title{
Serum vitamin D levels in acute stroke patients
}

Fayrouz O. Selim', Rasha M. Fahmi ${ }^{2^{*}}$ (D, Ayman E. Ali ${ }^{3}$, Nermin Raafat ${ }^{4}$ and Ahmed F. Elsaid ${ }^{5}$

\begin{abstract}
Background: Vitamin D deficiency has been proposed as a risk factors of cerebrovascular stroke.

Objectives: The aim of this study was firstly, to assess the serum level of vitamin D in cerebral stroke patients and secondly, to examine if its deficiency was associated with stroke severity and outcome.

Methods: We utilized a case-control study design and recruited 138 acute stroke patients and 138 age- and sexmatched controls from subjects attending outpatient clinic for other reasons. All participants were subjected to full general and neurological examination. Brain imaging $C T$ and/or MRI was performed. Blood samples were collected for measurement of serum level of vitamin D ( $\mathrm{ng} / \mathrm{ml}$ ) by ELISA, alkaline phosphatase, serum calcium, and phosphorous. The stroke severity was assessed by the National Institutes of Health Stroke Scale (NIHSS) and stroke outcome was assessed by modified Rankin Scale (mRS).

Results: Stroke patients had significant lower levels of vitamin D compared with the control group. Vitamin D deficiency remained significantly associated with the NIHSS stroke severity score and the mRS 3-month stroke outcome after controlling for other significant factors such as age, dyslipidemia, and infarction size using multivariable logistic regression analysis.

Conclusion: Our results demonstrated that stroke patients suffer from vitamin D deficiency, which was associated with both stroke severity and poor outcome. Vitamin D supplementation could exert a therapeutic role in the management of cerebral stroke.
\end{abstract}

Keywords: Vitamin D, Stroke, NIHSS, mRS

\section{Introduction}

Vitamin D is one of the fat-soluble steroid hormones which is responsible for calcium and phosphate homeostasis and musculoskeletal health. Vitamin D is synthesized from 7-dehydrocholesterol in the skin's epidermal layer in the presence of ultraviolet light. Then, undergo two hydroxylation steps: first inactive vitamin $\mathrm{D}$ is hydroxylated in the liver to form 25-hydroxyvitamin D, then classically in the kidney by 1 - $\alpha$-hydroxylase (CYP27B) to become biologically active form 1,25-dihydroxyvitamin $D_{3}$. The second hydroxylation step can also occur in macrophages, $T$ cells, and neurons $[1,2]$. Vitamin D has an important regulatory effect on immune function and inflammation [3]. Low vitamin D

\footnotetext{
* Correspondence: rashafahmi@zu.edu.eg

${ }^{2}$ Department of Neurology, Faculty of Medicine, Zagazig University, Sharkia, Egypt

Full list of author information is available at the end of the article
}

levels were associated with many illnesses such as calcium metabolism disorders, type 2 diabetes mellitus, autoimmune diseases, cardiovascular disease, stroke, multiple sclerosis, and some infectious diseases and cancers $[4,5]$.

Stroke is one of the most frequent causes of death and disability worldwide with a significant clinical and socioeconomic impact. It has a heterogeneous etiology including unmodifiable risk factors such as genetic, age and sex, and modifiable risk factors including hypertension, diabetes mellitus, dyslipidemia, sedentary lifestyle, and smoking [6]. Low serum vitamin D levels have been found in acute stroke patients compared with normal controls [6,7]. Vitamin D is essential for regulation of brain growth, function, and cerebrovascular physiology [8]. It has been linked to vasoprotective potential including slowing down of atherosclerosis, promotion of endothelial function, suppression of renin-angiotensin- 
aldosterone system thereby reduction of the risk of hypertension. Therefore, its deficiency might be involved in the development of several diseases, including diabetes, hypertension, heart failure, ischemic heart diseases, and stroke [9]. Moreover, deficiency of vitamin D influences vascular remodeling through modulation of smooth muscle cell proliferation, inflammation, and thrombosis. These vascular changes can eventually cause stroke [10].

However, results of different researches showed that vitamin D deficiency is a risk factor of stroke; the association between the severity and outcome of stroke with the level of vitamin D has not been examined closely. The aim of this study is to evaluate the serum vitamin D levels in cerebral stroke patients and assesses association between vitamin $\mathrm{D}$ deficiency with severity and outcome of stroke.

\section{Subjects and methods Sample size}

The sample size of the current case-control study was calculated based on the previously reported vitamin $\mathrm{D}$ deficiency rate of $48.8 \%$ in stroke patients and $31.6 \%$ in control subjects [6]. At 5\% two-sided level of significance, we found that a sample size of 260 subjects (130 subjects/group) to achieve a power of $80 \%$ using the Kelsey method, Epi Info, version 7.2 (CDC, 2018). We recruited 138 subjects for each of the case and control groups.

\section{Study design and subject recruitment}

We utilized a case-control study design that included 138 cerebral stroke patients and 138 control subjects from patients attending outpatient clinics for other reasons. Patients and control subjects were matched for sex and age \pm 5 years. Systemic random technique, recruiting every 3rd subject, was used for randomly selecting patients and control. Stroke patients were recruited from intensive care and stroke units of Internal Medicine and Neurology Departments, Zagazig University, between June 2016 and June 2017. All participants were informed with the study design and a written informed consent was collected from all participants or their relatives. Approval for performing the study was obtained from Institutional Review Board (IRB) of Zagazig University.

\section{Inclusion and exclusion criteria}

Any stroke patients with first-ever acute onset stroke were eligible for the study. We excluded patients with the following criteria: (1) patients with history of hepatic and renal impairment; (2) patients with brain neoplasm or malignancy; (3) patients with endocrinal diseases; (4) patients with vitamin D or Ca supplementation and steroid therapy; and (5) patients with bone diseases. Control included 138 healthy volunteers that were age and sex matched with no prior history of stroke or transient ischemic attacks.

\section{Brain imaging}

All patients were submitted to computed tomography (CT) using GE ProSpeed Dual Slice F II CT with MX135 Tube (Cleveland, USA) and/or magnetic resonance imaging (MRI) using $1.5 \mathrm{~T}$ MR Scanner (Achieva, Philips Medical System) of the brain on admission to differentiate patients with cerebral infarction from hemorrhage and to determine the site and size of the lesion. When there was no positive data on the admission CT scan, another CT scan or MRI was performed. The infarct size was determined by the largest diameter of the lesion [11].

\section{Laboratory investigations}

One venous blood sample was obtained for each subject. Blood samples were obtained within $48 \mathrm{~h}$ of the onset of stroke. Complete blood count (CBC), random blood glucose level, liver chemistry tests, kidney function tests, Creactive protein (CRP), arterial blood gases, serum sodium and potassium, erythrocyte sedimentation rate (ESR), lipid profile (total cholesterol, triglycerides, HDL, and LDL), alkaline phosphatase, serum calcium and phosphorous, and vitamin $\mathrm{D}$ were performed for all participant. Measurement of serum level of vitamin D (ng/ $\mathrm{ml}$ ) was done using enzyme-linked immunosorbent assay (ELISA) following manufacturer's instruction of the Kit (Immunodiagnostic Systems Ltd, Bolden, UK). The assay utilize as monoclonal antibody that binds to $25-\mathrm{OH}$ vita$\mathrm{min}_{3}$. Vitamin $\mathrm{D}$ deficiency was defined if its level was $<20 \mathrm{ng} / \mathrm{ml}[6]$.

\section{Stroke severity and outcome assessment}

The severity of the stroke was assessed by the National Institutes of Health Stroke Scale (NIHSS) [12]. Stroke severity was categorized as mild (NIHSS score < 8), moderate (NIHSS score 8-14), and severe stroke (NIHSS score $\geq 15$ ) [13]. Short-term functional outcome was measured using modified Rankin Scale (mRS) after 3 -months. mRS score of $\leq 2$ was considered as good functional outcome while poor functional outcome was defined as mRS score of $\geq 3$ [14].

\section{Other measures}

All patients of this study were subjected to detailed history taking with paying special attention to medical history of stroke risk factors, according to criteria determined by Mouradian and colleagues [15]. Full general and neurological examinations including Glasgow Coma Scale (GCS) were performed. Obesity is defined as body mass index $\geq 30 \mathrm{~kg} / \mathrm{m}^{2}$ [16]. Chest X-ray, 
electrocardiography, and echocardiography were done for patients with cardiac lesions.

\section{Statistical analysis}

Data were analyzed using the Statistical Package for the Social Sciences (SPSS) version 20 (IBM corporation, Armonk, New York) [17]. Quantitative variables were expressed as mean \pm standard deviation (SD), whereas qualitative variables were expressed as frequencies and percentages. Comparison between patients and controls was performed using Student $t$ test or chi-square test as deemed appropriate. Univariate followed by multivariable regression analysis was performed to identify independent significant factors associated with stroke severity and outcome. Measures of association were expressed as odds ratios (ORs) and 95\% confidence interval $(\mathrm{CI}) . p$ values $\leq 0.05$ and $\leq 0.01$ were considered significant and highly significant, respectively.

Partial correlation, after controlling of other significant risk factors, was performed to examine the association between vitamin D and NIHSS, and mRS scores was performed. We assessed the vitamin D cutoff levels associated with bad stroke severity and stroke outcome using the receiver-operating characteristic (ROC) analysis. Best sensitivity and specificity associated with cutoff levels was presented. ROC curve analysis was performed using the MedCalc software version 7.50 (Mariakerke, Belgium).

\section{Results}

This case-control study included 138 patients with a mean age $( \pm$ SD) of 64.27 years $( \pm 12.36)$, and 138 control subject with a mean age $( \pm$ SD) of 64.65 years $( \pm$ 10.2). According to stroke type, 30 (21.7\%) of our stroke patients had intracerebral hemorrhage, and 108 patients (78.3\%) had ischemic stroke (27.6\% had lacunar infarction, 32\% had medium-sized infarction, whereas only $18.7 \%$ presented with large infarction).

There were no statistically significant differences regarding age and sex. As regard to other risk factors, diabetes mellitus (DM) was significantly more common in stroke patients $(59.4 \%)$ followed by hypertension (58.7\%), obesity (42\%), dyslipidemia (40.6\%), smoking (33.3\%), atrial fibrillation (AF) (32.6\%), peripheral vascular disease (21.7\%), and ischemic heart disease (20.3\%) when compared with controls $(31.9 \%, 14.5 \%, 28.9 \%$, $13 \%, 8.7 \%, 7.2 \%, 3.6 \%$, and $8.7 \%$ respectively). Our studied stroke patients had statistically significant lower levels of vitamin D when compared with the control group. However, serum total $\mathrm{Ca}$, phosphorus, and alkaline phosphatase showed no statistically significant difference between patients and control (Table 1).

Stroke severity was assessed using NIHSS. Univariable analysis showed that age, hypertension, diabetes mellitus,
Table 1 Baseline characteristics of patients and control

\begin{tabular}{|c|c|c|c|c|}
\hline Variables & $\begin{array}{l}\text { Stroke } \\
\text { patients } \\
(N=138)\end{array}$ & $\begin{array}{l}\text { Control } \\
(N=138)\end{array}$ & $\begin{array}{l}\text { Test of } \\
\text { significant }\end{array}$ & $p$ value \\
\hline $\begin{array}{l}\text { Age (years): } \\
\text { mean } \pm S D\end{array}$ & $64.27 \pm 12.36$ & $64.65 \pm 10.2$ & $0.29^{a}$ & 0.33 \\
\hline \multicolumn{5}{|l|}{ Sex } \\
\hline Male & 72 (52.2\%) & 60 (43.5\%) & $2.09^{b}$ & 0.18 \\
\hline Females & $66(47.8 \%)$ & $78(56.5 \%)$ & & \\
\hline \multicolumn{5}{|l|}{$\begin{array}{l}\text { Vascular risk factors: } \\
N(\%)\end{array}$} \\
\hline Hypertension & 81 (58.7\%) & $20(14.5 \%)$ & $58.10^{b}$ & $0.000^{*}$ \\
\hline Diabetes mellitus & $82(59.4 \%)$ & 44 (31.9\%) & $21.08^{b}$ & $0.000^{*}$ \\
\hline Dyslipidemia & $56(40.6 \%)$ & $18(13 \%)$ & $26.66^{b}$ & $0.000^{*}$ \\
\hline Smoking & 46 (33.3\%) & 12 (8.7\%) & $25.23^{b}$ & $0.000^{*}$ \\
\hline Atrial fibrillation & $45(32.6 \%)$ & $10(7.2 \%)$ & $27.81^{b}$ & $0.000^{*}$ \\
\hline $\begin{array}{l}\text { Ischemic heart } \\
\text { disease }\end{array}$ & $28(20.3 \%)$ & $12(8.7 \%)$ & $7.48^{b}$ & $0.006^{*}$ \\
\hline $\begin{array}{l}\text { Peripheral vascular } \\
\text { disease }\end{array}$ & $30(21.7 \%)$ & $5(3.6 \%)$ & $20.45^{b}$ & $0.000^{*}$ \\
\hline Alcohol & $8(5.8 \%)$ & $4(2.9 \%)$ & $1.39^{b}$ & 0.37 \\
\hline Obesity & $58(42.0 \%)$ & $40(28.9 \%)$ & $5.12^{b}$ & $0.02^{*}$ \\
\hline \multicolumn{5}{|l|}{$\begin{array}{l}\text { Laboratory findings: } \\
\text { mean } \pm \text { SD }\end{array}$} \\
\hline $\begin{array}{l}\text { Calcium level } \\
(\mathrm{mg} / \mathrm{dl})\end{array}$ & $8.69 \pm 0.92$ & $8.73 \pm 0.99$ & $0.34^{\mathrm{a}}$ & 0.63 \\
\hline $\begin{array}{l}\text { Phosphorus level } \\
\text { (mg/dl) }\end{array}$ & $3.96 \pm 0.69$ & $4.06 \pm 0.54$ & $1.34^{\mathrm{a}}$ & 0.18 \\
\hline Vitamin D (ng/ml) & $13.47 \pm 7.04$ & $37.62 \pm 4.4$ & $34.17^{a}$ & $0.000^{*}$ \\
\hline $\begin{array}{l}\text { Alkaline } \\
\text { phosphatase }(\mu / L)\end{array}$ & $68.43 \pm 19.6$ & $66.65 \pm 20.82$ & $0.73^{a}$ & 0.46 \\
\hline \multicolumn{5}{|c|}{$\begin{array}{l}N \text { Number, SD standard deviati } \\
{ }^{a} t \text { test } \\
{ }^{b} \text { Chi-squared } \\
{ }^{*} \text { Significant at } p \text { value } \leq 0.05\end{array}$} \\
\hline
\end{tabular}

dyslipidemia, AF, vitamin D deficiency, CRP, large infarction size, and intracerebral hemorrhage were significantly associated with stroke severity. Further multivariable analysis of the significant variables showed that old age $(\mathrm{OR}=1.072)$, dyslipidemia $(\mathrm{OR}=3.588)$, vitamin $\mathrm{D}$ deficiency $(\mathrm{OR}=4.790)$, and large infarction size $(O R=7.462)$ was independently associated with stroke severity. The odds to have severe stroke is 1 with old age $(\mathrm{OR}=1.072), 3$ with dyslipidemia $(\mathrm{OR}=3.588)$, and increased to be almost 5 with vitamin $\mathrm{D}$ deficiency $(\mathrm{OR}=4.790)$, and 7 with large infarction size $(\mathrm{OR}=$ 7.462) (Table 2).

As regards stroke outcome using mRS, hypertension, diabetes mellitus, dyslipidemia, vitamin D deficiency, CRP, GCS, NIHSS, large infarction size, and intracerebral hemorrhage were significantly associated with bad outcome. Multivariable analysis was used to analyze the association of significant factors with stroke outcome in 
Table 2 Univariable and Multivariable Logistic Regression analysis of factors with stroke severity (NIHSS)

\begin{tabular}{|c|c|c|c|c|c|c|}
\hline \multirow[t]{2}{*}{ Variables } & \multicolumn{3}{|c|}{ Univariate } & \multicolumn{3}{|c|}{ Multivariate } \\
\hline & $\mathrm{OR}$ & $95 \% \mathrm{Cls}$ & $p$ value & $\mathrm{OR}$ & $95 \% \mathrm{Cls}$ & $p$ value \\
\hline Age & 1.057 & $1.017-1.098$ & $0.005^{*}$ & 1.072 & $1.016-1.130$ & $0.01^{*}$ \\
\hline Hypertension & 3.795 & $1.441-9.994$ & $0.007^{*}$ & 2.889 & $0.822-10.153$ & 0.09 \\
\hline Diabetes mellitus & 2.897 & $1.150-7.296$ & $0.02^{*}$ & 1.446 & $0.442-4.727$ & 0.54 \\
\hline Dyslipidemia & 3.586 & $1.551-8.289$ & $0.003^{*}$ & 3.588 & $1.240-10.382$ & $0.01 *$ \\
\hline Smoking & 1.620 & $0.711-3.688$ & 0.251 & & & \\
\hline Atrial fibrillation & 2.406 & $1.059-5.469$ & $0.03^{*}$ & 1.489 & $0.500-4.433$ & 0.47 \\
\hline Ischemic heart disease & 1.513 & $0.591-3.873$ & 0.38 & & & \\
\hline Peripheral vascular disease & 1.065 & $0.408-2.782$ & 0.89 & & & \\
\hline Alcohol & 1.161 & $0.222-6.061$ & 0.86 & & & \\
\hline Obesity & 1.955 & $0.872-4.384$ & 0.10 & & & \\
\hline Vitamin D deficiency & 3.921 & $1.399-10.993$ & $0.009^{*}$ & 4.790 & $1.282-17.903$ & $0.02^{*}$ \\
\hline CRP & 2.706 & $1.179-6.213$ & $0.01^{*}$ & 1.711 & $0.581-5.033$ & 0.32 \\
\hline GCS & 0.875 & $0.755-1.015$ & 0.08 & & & \\
\hline Intracerebral hemorrhage & 3.123 & $1.292-7.548$ & $0.01^{*}$ & 3.217 & $0.876-11.812$ & 0.08 \\
\hline \multicolumn{7}{|l|}{ Infarction size: } \\
\hline Small (reference) & 1 & & & & & \\
\hline Medium & 1.706 & $0.644-4.515$ & 0.28 & 1.716 & $0.466-6.324$ & 0.41 \\
\hline Large & 4.253 & $1.522-11.884$ & $0.006^{*}$ & 7.462 & $1.795-31.030$ & $0.006^{*}$ \\
\hline
\end{tabular}

CRP C-reactive protein, GCS Glasgow Coma Scale, NIHSS National Institute of Health Stroke Scale, OR odds ratio, $\mathrm{Cl}$ confidence interval

*Significant at $p$ value $\leq 0.05$

univariable analysis. NIHSS score, vitamin D deficiency, and large infarction size were significant independent risk factors associated with stroke outcome. The odds to have bad outcome increase from 1 with high NIHSS score $(\mathrm{OR}=1.094)$ to 2.8 with vitamin $\mathrm{D}$ deficiency $(\mathrm{OR}$ $=2.899)$ and 3.7 with large infarction size $(\mathrm{OR}=3.774)$ (Table 3).

Partial correlation of vitamin D serum level with NIHSS stroke severity score after controlling for age, dyslipidemia, and infarction size was done, and a significant negative correlation was found between vitamin D serum level and NIHSS $(p=0.002, r=-$ 0.267) (Fig. 1). Also, partial correlation of vitamin D serum level with mRS stroke outcome score after controlling for NIHSS and infarction size was done and a significant negative correlation was found between serum vitamin D level and mRS ( $p=0.01, r=$ - 0.207) (Fig. 2).

Receiver operator characteristics (ROC) curve analysis of vitamin $\mathrm{D}$ serum level that best predict stroke severity as determined by NIHSS score was used. Vitamin D serum level of $\leq 9 \mathrm{ng} / \mathrm{ml}$ was shown to predict stroke severity with sensitivity of $74.2 \%$ and specificity of $71 \%$. The overall performance of vitamin D marker was $77 \%$ as determined by area under curve (AUC) and was significantly different from the $50 \%$ chance diagonal line ( $p$ $<0.0001$ ) (Fig. 3).
Moreover, using the ROC curve analysis, we tested the vitamin $\mathrm{D}$ serum level that best predict stroke outcome as determined by mRS score. Vitamin D serum level of $\leq 17 \mathrm{ng} / \mathrm{ml}$ was shown to predict stroke outcome with sensitivity of $81.4 \%$ but with low specificity of $42.7 \%$. The overall performance of vitamin D marker was $65.4 \%$ as determined by area under curve (AUC) that was significantly different from the $50 \%$ chance diagonal line $(p<0.001)$ (Fig. 4$)$.

\section{Discussion}

In the current study, the most prevalent risk factors of stroke were all modifiable. Diabetes mellitus was the most common followed by hypertension, obesity, dyslipidemia, smoking, AF, peripheral vascular disease, ischemic heart disease, and vitamin D deficiency. In general, this result was in agreement with the results derived from many previous epidemiological studies $[18,19]$. Strong evidence for the association of low vitamin D with higher risk of cerebral stroke stems from several meta-analyses studies $[20,21]$. The incidence of cerebral stroke was reported to increase by more than double in the presence of ischemic heart disease, more than triple in the presence of hypertension, more than quadruple in the presence of heart failure, and nearly quintupled when AF was present [22]. In the present study, stroke patients had 
Table 3 Univariable and multivariable logistic regression analysis of factors with stroke outcome (mRS)

\begin{tabular}{|c|c|c|c|c|c|c|}
\hline \multirow[t]{2}{*}{ Variables } & \multicolumn{3}{|c|}{ Univariate } & \multicolumn{3}{|c|}{ Multivariate } \\
\hline & $\mathrm{OR}$ & $95 \% \mathrm{Cls}$ & $p$ value & $\mathrm{OR}$ & $95 \% \mathrm{Cls}$ & $p$ value \\
\hline Age & 1.026 & $0.994-1.059$ & 0.11 & & & \\
\hline Hypertension & 2.974 & $1.278-6.921$ & $0.01^{*}$ & 2.385 & $0.843-6.749$ & 0.10 \\
\hline Diabetes mellitus & 2.857 & $1.228-6.650$ & $0.01^{*}$ & 1.521 & $0.550-4.207$ & 0.41 \\
\hline Dyslipidemia & 2.294 & $1.073-4.906$ & $0.03^{*}$ & 1.325 & $0.513-3.422$ & 0.56 \\
\hline Smoking & 1.982 & $0.916-4.288$ & 0.08 & & & \\
\hline Atrial fibrillation & 1.522 & $0.699-3.315$ & 0.29 & & & \\
\hline Ischemic heart disease & 0.849 & $0.328-2.198$ & 0.73 & & & \\
\hline Peripheral vascular disease & 0.455 & $0.160-1.291$ & 0.14 & & & \\
\hline Alcohol & 2.824 & $0.669-11.918$ & 0.16 & & & \\
\hline Obesity & 1.004 & $0.471-2.140$ & 0.991 & & & \\
\hline Vitamin D deficiency & 3.480 & $1.400-8.647$ & $0.007^{*}$ & 2.899 & $1.003-8.384$ & $0.04^{*}$ \\
\hline CRP & 2.300 & $1.072-4.936$ & $0.03^{*}$ & 1.407 & $0.550-3.602$ & 0.47 \\
\hline GCS & 0.843 & $0.732-0.971$ & $0.02^{*}$ & 0.883 & $0.744-1.049$ & 0.15 \\
\hline $\mathrm{NIHSS}$ & 1.151 & $1.074-1.233$ & $0.000^{*}$ & 1.094 & $1.014-1.182$ & $0.02^{*}$ \\
\hline Intracerebral hemorrhage & 2.539 & $1.086-5.936$ & $0.03^{*}$ & 2.821 & $0.867-9.173$ & 0.08 \\
\hline \multicolumn{7}{|l|}{ Infarction size } \\
\hline Small (reference) & 1 & & & & & \\
\hline Medium & 1.774 & $0.732-4.303$ & 0.20 & 1.909 & $0.644-5.656$ & 0.24 \\
\hline Large & 3.626 & $1.361-9.660$ & $0.01^{*}$ & 3.774 & $1.049-13.581$ & $0.04^{*}$ \\
\hline
\end{tabular}

CRP C-reactive protein, GCS Glasgow Coma Scale, NIHSS National Institute of Health Stroke Scale, OR odds ratio, CI confidence interval

*Significant at $p$ value $\leq 0.05$

statistically significant lower levels of vitamin D when compared with control group. This was concomitant with non-significant reduction of lower serum total $\mathrm{Ca}$ and phosphorus and increased alkaline phosphatase levels in stroke patients compared with controls.
These results were in agreement with the results obtained by other studies [23-26].

The association of vitamin D deficiency with stroke severity and outcome after controlling for other risk factors suggests a role for vitamin $\mathrm{D}$ in the pathogenesis of

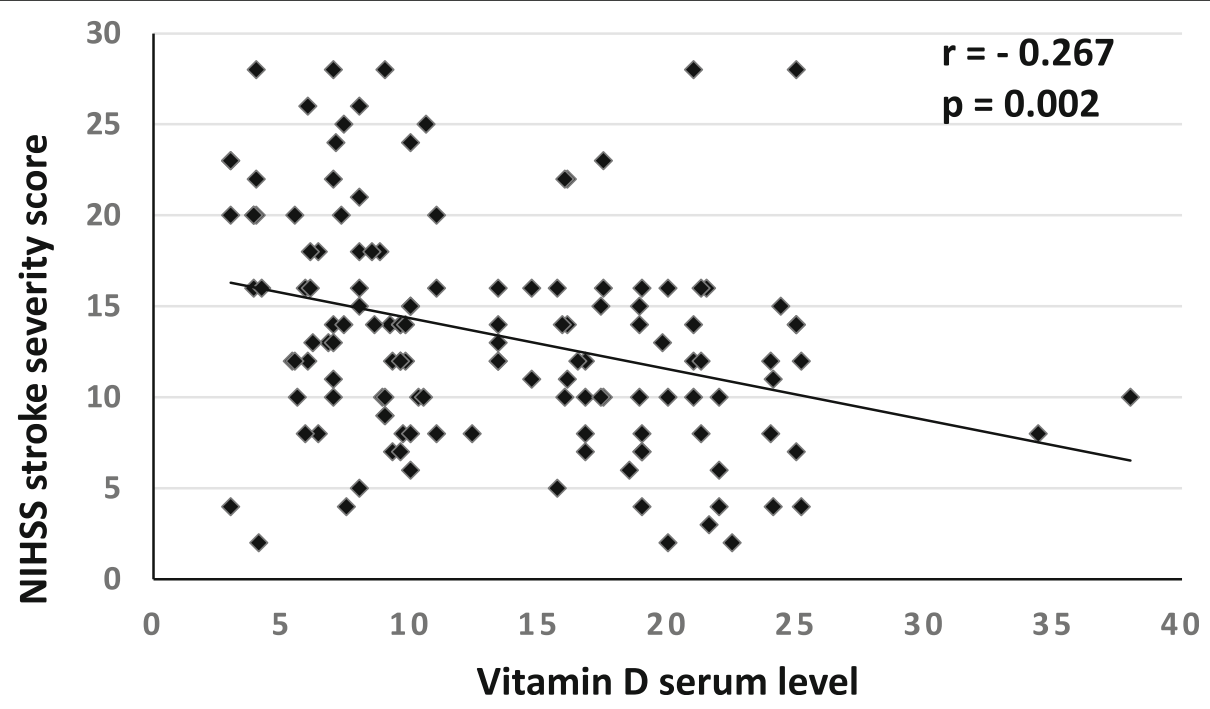

Fig. 1 Partial correlation analysis after controlling for age, dyslipidemia, and infarction size shows that vitamin D serum level (ng/ml) demonstrated significant negative correlation with NIHSS stroke severity score 


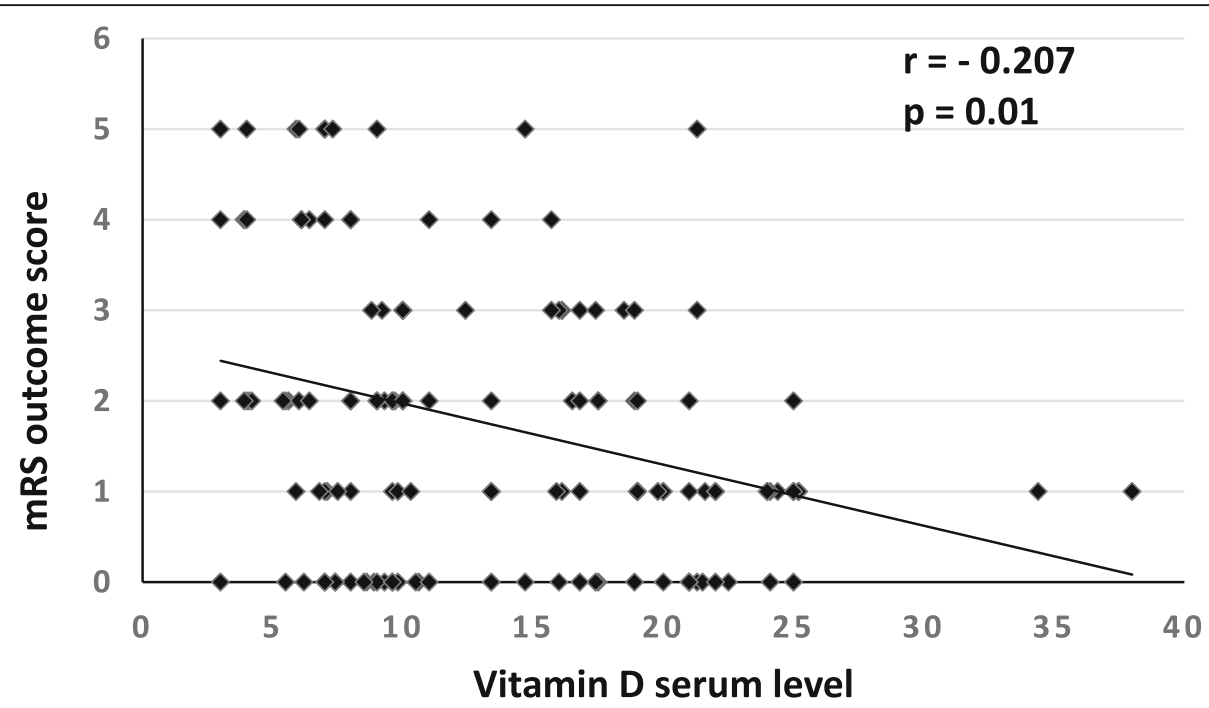

Fig. 2 Partial correlation analysis after controlling for NIHSS score and infarction size shows that vitamin D serum level (ng/ml) demonstrated significant negative correlation with mRS stroke outcome score

stroke that could be invoked by several mechanisms. For example, vitamin $\mathrm{D}$ has a role in arterial hypertension via the suppression of the renin-angiotensin-aldosterone system (RAS). RAS is a key regulator of blood pressure, electrolyte, and volume homeostasis. Overactivation of the RAS system leads to hypertension which is one of the most important modifiable risk factor for all

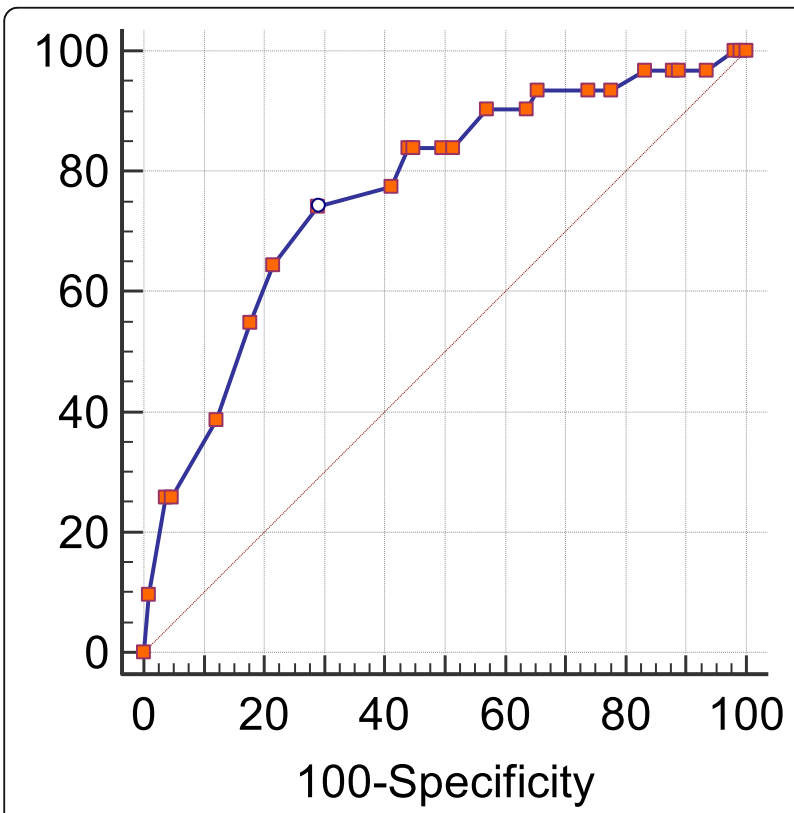

Fig. 3 Receiver operator characteristics (ROC) analysis showed that vitamin D serum level $\leq 9 \mathrm{ng} / \mathrm{ml}$ best predict stroke severity (as determined by NIHSS score) with sensitivity and specificity of $74.2 \%$ and $71 \%$, respectively. Area under curve (AUC) of $77 \%$ was significantly different from the random $50 \%(p<0.0001)$ types of stroke [27, 28]. Type 2 diabetes was associated with low vitamin D levels, which was linked to pancreatic $\beta$ cell dysfunction and disturbed insulin secretion [29]. In addition, vitamin $D$ acts as a modulator of depolarization potential and stimulated insulin secretion via releasing of intracellular calcium stores [30]. Moreover, vitamin D regulates parathyroid hormone $(\mathrm{PTH})$

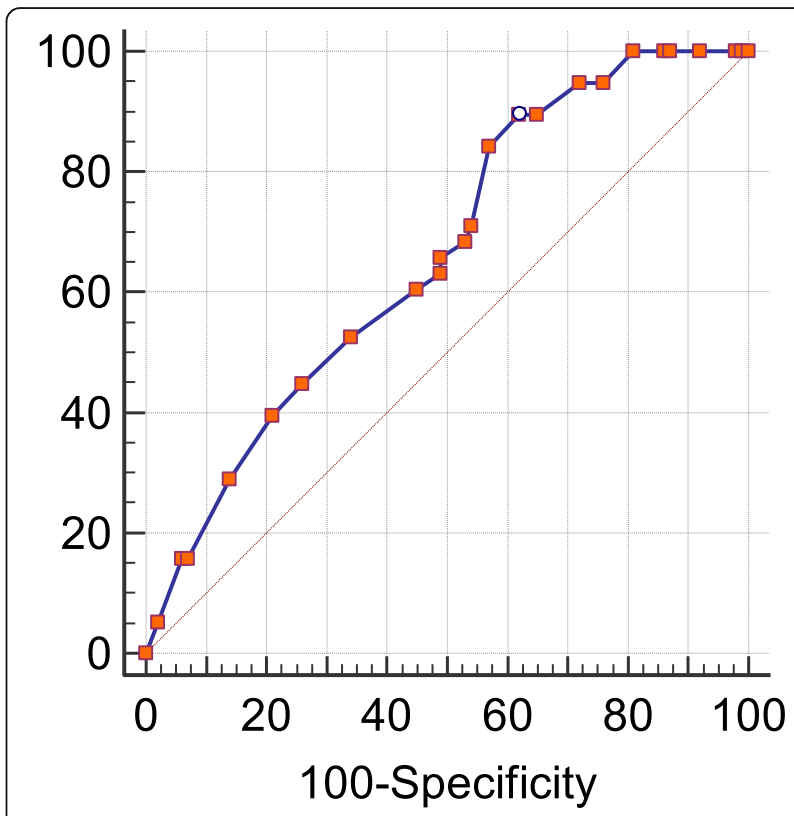

Fig. 4 Receiver operator characteristics (ROC) analysis showed that vitamin D serum level $-17 \mathrm{ng} / \mathrm{ml}$ that best predict stroke outcome (as determined by mRS score) with sensitivity and specificity of $81.4 \%$ and $42.7 \%$, respectively. Area under curve (AUC) was $65.4 \%$ was significantly different from the random $50 \%(p<0.001)$ 
concentration which is associated with insulin synthesis and secretion in the pancreas [29]. Vitamin D deficiency induces secondary hyperparathyroidism and increased PTH level that was associated with diabetes by causing $\beta$ cell dysfunction and insulin resistance [30]. Furthermore, vitamin $\mathrm{D}$ deficiency was shown to be associated with dyslipidemia among stroke patients [31, 32]. It was observed that low vitamin $\mathrm{D}$ concentrations were associated with higher triglycerides and total cholesterol and lower levels of HDL cholesterol [31]. In this study, the results of multivariable logistic regression analysis showed that after controlling other risk factors, age, dyslipidemia, vitamin D deficiency, and large infarction size were statistically significant independent factors associated with stroke severity. This was in agreement with other studies which showed that vitamin D deficiency was associated with stroke severity [25, 33]

Regarding stroke outcome, multivariable logistic regression analysis showed that high NIHSS score, vitamin $\mathrm{D}$ deficiency, and large infarction size were significantly associated with mRS. Our result was in accordance with the result of other studies demonstrated that vitamin D level is a good biomarker for prognosis, functional outcome, and death in patients with acute ischemic and hemorrhagic stroke $[25,26,33,34]$. This could be explained by the neuroprotection role of vitamin $D$ via activation of detoxification pathways, upregulation of antioxidation/anti-inflammatory mechanisms, inhibition of inducible nitric oxide synthase, and regulation of neuronal calcium metabolism $[35,36]$. Interestingly, the result of a recent experimental trial demonstrated that administration of vitamin D can attenuate infarct development after stroke probably by modulating the inflammatory response to cerebral ischemia [37].

In the current study, partial correlation of vitamin D serum level with NIHSS score severity and mRS score outcome after controlling for other variables showed a significant negative correlation between serum vitamin D level with stroke severity and outcome. Furthermore, ROC curve analysis of vitamin D serum level that best predict stroke severity was $\leq 9 \mathrm{ng} / \mathrm{ml}$ and vitamin $\mathrm{D}$ serum level of $\leq 17 \mathrm{ng} / \mathrm{ml}$ was the best cutoff for stroke outcome. Our finding was in agreement with other studies reported $10-12 \mathrm{ng} / \mathrm{mL}$ as the best cutoff value of vitamin $\mathrm{D}$ for mortality $[38,39]$. However, another study estimated a higher cutoff value of serum $25(\mathrm{OH})$ D levels as indicator for early neurological deterioration to be $42.5 \mathrm{nmol} / \mathrm{l}$ [40]. These cutoff values could be used to identify patients at a higher risk of severe stroke and bad outcome that need more intensive monitoring.

Some limitations of our study include enrolling patients over different seasons. It is known that vitamin D levels exhibits some seasonal variation. In addition, we did not collect information regarding previous dietary intake and sunlight exposure. Unavailable data on serum parathyroid hormone represent another limitation.

In conclusion, our results demonstrated that vitamin $\mathrm{D}$ deficiency was an independent risk factor significantly associated with cerebral stroke severity and outcome after controlling other known risk factors. This result suggests a therapeutic role for vitamin D supplementation in the management of cerebral stroke. Further prospective studies are needed to verify whether correcting vitamin $\mathrm{D}$ deficiency may affect the severity and outcome of the stroke as well as to establish the appropriate therapeutic dose of vitamin D for supplementation in stroke patients. Screening for serum vitamin D concentrations is likely to identify individuals who are at the highest risks, particularly those with old age, diabetes, and large infarction.

\section{Abbreviations}

CBC: Complete blood count; Cl: Confidence interval; CRP: C-reactive protein; $C T$ : Computed tomography; ESR: Erythrocyte sedimentation rate; GCS: Glasgow Coma Scale; IRB: Institutional Review Board; MRI: Magnetic resonance imaging; mRS: Modified Rankin Scale; N: Number; NIHSS: National Institutes of Health Stroke Scale; OR: Odds ratio; ROC: Receiver operator characteristics; SD: Standard deviation

\section{Acknowledgements}

Not applicable

\section{Authors' contributions}

FOS, RMF, AEA, NR, and AFE contributed to the design of the study, data collection, analyzed, and interpreted the data. All authors were responsible for writing the manuscript, guidance, and follow-up the final revision. All authors were involved in drafting the article or revising it critically for important intellectual content. All authors approved the final version to be published.

\section{Funding}

This study received no funding.

Availability of data and materials

The data results generated or analyzed during this study are included in this published article.

\section{Ethics approval and consent to participate}

The study protocol was approved by the ethics committee of the faculty of Medicine, Zagazig University. The reference number is 3836/21-6-2017. The purpose of the study was explained, and an informed written consent was taken before taking any data or doing any investigations. The participants were informed that their participation was voluntary and that they could withdraw from the study at any time without consequences.

Consent for publication

Is not applicable in this section.

\section{Competing interests}

The authors declare that they have no competing interests.

\section{Author details}

${ }^{1}$ Department of Internal Medicine, Zagazig University, Sharkia, Egypt. ${ }^{2}$ Department of Neurology, Faculty of Medicine, Zagazig University, Sharkia, Egypt. ${ }^{3}$ Department of Internal Medicine, Zagazig University, Sharkia, Egypt. ${ }^{4}$ Department of Medical Biochemistry, Zagazig University, Sharkia, Egypt. ${ }^{5}$ Department of Public Health and Community Medicine, Zagazig University, Sharkia, Egypt. 
Received: 20 March 2019 Accepted: 6 November 2019

Published online: 09 December 2019

\section{References}

1. Holick MF. Vitamin D deficiency, N Engl J Med. 2007:357:266.

2. Lugg ST, Howells PA, Thickett DR. Optimal vitamin D supplementation levels for cardiovascular disease protection. Dis Markers. 2015;2015:1.

3. Clancy N, Onwuneme C, Carroll A, McCarthy R, McKenna MJ, Murphy N, et al. Vitamin D and neonatal immune function. J Matern Fetal Neonatal Med. 2013;26:639.

4. Wacker M, Holick MF. Vitamin D effects on skeletal and extraskeletal health and the need for supplementation. Nutrients. 2013;5:111.

5. Fahmi RM, Lotfy SM, Mohamed WS, Elsaid AF, Murad MH, Abdulmoneem G. Vitamin D levels in patients with multiple sclerosis. Egypt J Neurol Psychiatr Neurosurg. 2014:51:145.

6. Chaudhuri JR, Mridula KR, Alladi S, Umamahesh M, Balaraju B, Swath A, et al. Serum 25-hydroxyvitamin D deficiency in ischemic stroke and subtypes in Indian patients. J STROKE. 2014;16:44.

7. Alfieri DF, Lehmann MF, Oliveira SR, Flauzino T, Delongui F, de Araújo MC, et al. Vitamin D deficiency is associated with acute ischemic stroke, Creactive protein, and short-term outcome. Metab Brain Dis. 2017;32:493.

8. Eyles DW, Liu PY, Josh P, Cui X. Intracellular distribution of the vitamin D receptor in the brain: comparison with classic target tissues and redistribution with development. Neuroscience. 2014:268:1.

9. Carvalho LS, Sposito AC. Vitamin D for the prevention of cardiovascular disease: are we ready for that? Atherosclerosis. 2015;241:729.

10. Thapa L, Pokhrel B, Shrestha A, Pradhan M, Bhandari TR, Shrestha S, et al. Status of vitamin $D$ and its association with stroke risk factors in patients with acute ischemic stroke in a tertiary care hospital. J Nepal Med Assoc. 2014;52:935.

11. Shine P, Shwu W, Tzy W, Lee TK, Tony C. Location and size of infarct on functional outcome of non cardioembolic ischemic stroke. Disabil Rehabil. 2006:28:977

12. Brott T, Adams HP, Olinger CP, Marler JR, Barsan WG, Biller J, et al. Measurements of acute cerebral infarction: a clinical examination scale. Stroke. 1989;20:864.

13. NIH Stroke Scale. National Institute of Neurological Disorder website. https:// www. ninds.nih.gov/sites/default/files/NIH_Stroke_Scale.

14. Uyttenboogaart M, Stewart RE, Vroomen PC, De Keyser J, Luijckx GJ. Optimizing cutoff scores for the Barthel index and the modified Rankin Scale for defining outcome in acute stroke trials. Stroke. 2005;36:1984.

15. Mouradian MS, Majumdar SR, Senthilselvan A, Khan K, Shuaib A. How well are hypertension, hyperlipidemia, diabetes, and smoking managed after a stroke or transient ischemic attack? Stroke. 2002;33:1656.

16. Organization WHO. Obesity and overweight. World Health Organization. http://www.who.int/mediacentre/factsheets/fs311/en/.

17. Corp IBM. IBM SPSS Statistics for Windows, Version 20. IBM Corp: Armonk NY; 2010.

18. Kissela BM, Khoury JC, Alwell K, Moomaw CJ, Woo D, Adeoye O, et al. Age at stroke: temporal trends in stroke incidence in a large, biracial population. Neurology. 2012;79:1781.

19. Smajlović D. Strokes in young adults: epidemiology and prevention. Vasc Health Risk Manag. 2015;11:157.

20. Zhou R, Wang M, Huang H, Li W, Hu Y, Wu T. Lower vitamin D status is associated with an increased risk of ischemic stroke: a systematic review and meta-analysis. Nutrients. 2018;10:277.

21. Brondum-Jacobsen P, Nordestgaard BG, Schnohr P, Benn M. 25hydroxyvitamin D and symptomaticischemic stroke: an original study and meta-analysis. Ann Neurol. 2013;73:38

22. Wolf PA, Abbott RD, Kannel WB. Atrial fibrillation as an independent risk factor for stroke: the Framingham Study. Stroke. 1991;22:983.

23. Alfieri DF, Lehmann MF, Oliveira SR, Flauzino T, Delongui F, de Araújo MC, et al. Vitamin D deficiency is associated with acute ischemic stroke, Creactive protein, and short-term outcome. Metab Brain Dis. 2017:32:493.

24. Chatterjee K, Mandal SK, Chatterjee S. Assessment of vitamin D level in cerebrovascular accident patients in Eastern India. Natl J Med Res. 2014:4:264

25. Fahmy E, Sharaf S, Helmy H, Sherif S. Vitamin D status in acute ischemic stroke: relation to initial severity and short-term outcome. Egypt J Neurol Psychiatr Neurosurg. 2019; 55: 18
26. Wajda J, Świat M, Owczarek AJ, Brzozowska A, Glinianowicz MO, Chudek J. Severity of vitamin D deficiency predicts mortality in ischemic stroke patients. Dis Markers. 2019;2019:1.

27. Kannel WB, Wolf PA. Framingham study insights on the hazards of elevated blood pressure. JAMA. 2008;300:2545

28. Santoro D, Caccamo D, Lucisano S, Buemi M, Sebekova K, Teta D, et al. Interplay of vitamin D, erythropoiesis, and the renin-angiotensin system. Bio Med Res Int. 2015;2015:1.

29. Afzal S, Bojesen SE, Nordestgaard BG. Low 25-hydroxyvitamin D and risk of type 2 diabetes: a prospective cohort study and metaanalysis. Clin Chem. 2013;59:381

30. Song Y, Wang L, Pittas AG, Del Gobbo LC, Zhang C, Manson JE, et al. Blood 25-hydroxy vitamin D levels and incident type 2 diabetes: a meta-analysis of prospective studies. Diabetes care. 2013;36:1422.

31. Ponda MP, Huang XX, Odeh MA, Breslow JL, Kaufman HW. Vitamin D may not improve lipid levels: a serial clinical laboratory data study. Circulation. 2012;126:270

32. Zittermann AF, Gummert J, Borgermann J. The role of vitamin D in dyslipidemia and cardiovascular disease. Curr Pharm Design. 2011;17:933.

33. Tu WJ, Zhao SJ, Xu DJ, Chen H. Serum 25-hydroxyvitamin D predicts the short-term outcomes of Chinese patients with acute ischaemic stroke. Clin Sci. 2014;126:339.

34. Park KY, Chung PW, Kim YB, Moon HS, Suh BC, Won YS, et al. Serum vitamin D status as a predictor of prognosis in patients with acute ischemic stroke. Cerebrovasc Dis. 2015;40:73.

35. Michos ED, Gottesman RF. Vitamin D for the prevention of stroke incidence and disability: promising but too early for prime time. Eur J Neurol. 2013;20:3.

36. Witham MD, Dove FJ, Sugden JA, Doney AS, Struthers AD. The effect of vitamin D replacement on markers of vascular health in stroke patients-a randomised controlled trial. Nutr Metab Cardiovas. 2012;22:864.

37. Evans MA, Kim HA, Ling YH, Uong S, Vinh A, De Silva TM, et al. Vitamin D3 supplementation reduces subsequent brain injury and inflammation associated with ischemic stroke. Neuromol Med. 2018:20:147.

38. Moraes RB, Friedman G, Wawrzeniak C, Marques LS, Nagel FM, Lisboa TC, etal. Vitamin $\mathrm{D}$ deficiency is independently associated with mortality among critically ill patients. Clinics (Sao Paulo). 2015; 70: 326

39. Venkatram S, Chilimuri S, Adrish M, Salako A, Patel M, Diaz-Fuentes G. Vitamin $D$ deficiency is associated with mortality in the medical intensive care unit. Crit Care. 2011:15:R292.

40. Hu W, Liu D, Qin L, Wang L, Tang Q, Wang G. Decreasing serum 25hydroxyvitamin D levels and risk of early neurological deterioration in patients with ischemic stroke. Brain and Behav. 2019:9:1227.

\section{Publisher's Note}

Springer Nature remains neutral with regard to jurisdictional claims in published maps and institutional affiliations.

\section{Submit your manuscript to a SpringerOpen ${ }^{\circ}$ journal and benefit from:}

- Convenient online submission

- Rigorous peer review

- Open access: articles freely available online

- High visibility within the field

- Retaining the copyright to your article

Submit your next manuscript at $>$ springeropen.com 